\title{
The diet of adolescents can be improved by school intervention
}

\author{
Ulla Hoppu ', Jenni Lehtisalo', Johanna Kujala', Teija Keso², Sini Garam², \\ Heli Tapanainen ${ }^{1}$, Antti Uutela ${ }^{1}$, Tiina Laatikainen ${ }^{1}$, Ulla Rauramo ${ }^{2}$ and Pirjo Pietinen ${ }^{1, *}$ \\ ${ }^{1}$ National Institute for Health and Welfare, PO Box 30, FI-00271 Helsinki, Finland: ${ }^{2}$ Finnish Bread Information, \\ Helsinki, Finland
}

Submitted 20 July 2009: Accepted 15 March 2010

\begin{abstract}
Objective: To decrease the intake of sucrose, increase the intake of fibre and the consumption of fruit and vegetables among secondary-school pupils.

Design: Intervention study among eighth grade pupils during one school year. Data were collected by questionnaires and from a subgroup of pupils by $48 \mathrm{~h}$ dietary recall at baseline in spring 2007 and after the intervention in 2008.

Setting: Twelve secondary schools were randomly allocated to intervention (IS) and control schools (CS) within three cities. Intervention included nutrition education and improvement of the food environment focusing particularly on the quality of snacks at school.

Subjects: A total of 659 pupils completed the questionnaires and the dietary recall was obtained from 287 pupils both at baseline and follow-up.

Results: The frequency of consumption of rye bread increased $(P=0 \cdot 03)$ and that of sweets decreased $(P=0.006)$ among girls in the IS. The intake of sucrose fell among IS pupils, from $12 \cdot 8 \%$ to $10 \cdot 5 \%$ of the total energy intake $(P=0 \cdot 01)$. Intake of fruit $(\mathrm{g} / \mathrm{MJ})$ remained the same in IS, whereas it decreased in CS $(P=0 \cdot 04)$.

Conclusions: Sugar intake can be lowered by improving the quality of snacks, but it is more difficult to increase fibre intake and fruit and vegetable consumption unless the content of school lunches can be modified. It is the responsibility of the adults working in schools to create a healthy environment and to make healthy choices easy for pupils.
\end{abstract}

Unhealthy dietary habits of children and adolescents are a growing public health problem in many countries. Schools are good operational environments to promote healthy eating habits both via teaching and school meals. Various interventions in school settings have been conducted during previous years with variable results ${ }^{(1,2)}$. Many previous interventions have had a focus on overweight and obesity, and have, in addition to diet, concentrated on increasing physical activity ${ }^{(3,4)}$.

Curriculum and school meal arrangements may differ a great deal between countries, and, therefore, more research is needed to find effective local practices for health promotion. In Finland, the free school lunch prepared according to national recommendations provides a good basis for the diet of adolescents ${ }^{(5,6)}$. However, it has been observed that not all pupils eat the lunch every day, or at least not all components of it (main course, bread, salad and milk). Despite the recommendations, the selling of unhealthy snacks is still common in Finnish schools ${ }^{(7)}$, and in many schools the possibility of leaving the school premises attracts pupils to go to nearby shops to buy unhealthy snacks. Teaching of home economics and health education are good tools to deliver information and skills to secondary-school pupils, but themes of healthy eating may also be incorporated into other lessons.

Many factors influence adolescents' eating behaviours ${ }^{(8)}$. Individual characteristics include psychosocial factors such as attitudes, beliefs, knowledge, taste and food preferences as well as biological factors (hunger and gender) and lifestyle factors (time and convenience, dieting, etc.). Adolescents' eating behaviours are also strongly influenced by their social environment that includes family, friends and teachers. The physical environment influences accessibility and availability of foods, e.g. from vending machines at schools. Understanding these factors is important in order to develop effective nutrition interventions to change the eating habits of adolescents ${ }^{(8)}$.

Previous studies have indicated that the intake of fruit and vegetables is low and that the consumption of unhealthy, sugary snacks is common among adolescents in Finland ${ }^{(9)}$. Therefore, the main objectives of this intervention study were to decrease the intake of sucrose, increase the intake of fibre and consumption of fruit and vegetables. Specifically, the aims were to increase consumption of the full school lunch and to change the snacks eaten during school hours into healthier options. 


\section{Subjects and methods}

\section{Subjects and study protocol}

Altogether twelve schools in three cities agreed to participate. A detailed description of the recruitment of schools has been published in the baseline article ${ }^{(10)}$. The study protocol was approved by the ethical committee of the Hospital District of Helsinki and Uusimaa.

There were 1469 seventh grade pupils in these schools and 769 pupils (52\%) agreed to participate in the study. However, since the intervention was implemented as part of normal teaching, it was targeted at all pupils, not just the participants.

The baseline study for the seventh grade pupils was performed in April-May 2007. After the baseline study, the schools were randomised into intervention (IS) and control schools (CS) within the cities. Thus, there were three IS and three CS in Tampere, two IS and two CS in Lahti and one IS and one CS in Mikkeli. Intervention for the eighth graders was started at the beginning of the school year (August 2007) and continued until the follow-up study (April 2008). At baseline, the participants were on average 13.8 years old. The sociodemographic characteristics of participants (parents' education and employment) differed between single schools but were comparable between IS and CS as a group (data not shown).

Structured questionnaires including questions about eating habits and frequency of food use were sent to pupils' homes by post. Altogether 659 adolescents returned their questionnaires both in 2007 and 2008. Computer-assisted $48 \mathrm{~h}$ dietary recalls were performed for a randomly selected subgroup of participants (altogether 287 in both years). Dietary interviews were performed at schools by trained nutritionists during school hours. A detailed description of the methodology can be found in the baseline article ${ }^{(10)}$.

\section{Statistical methods}

All the seventh grade pupils in twelve study schools were invited to participate in the study. This cluster sampling was taken into account in all analyses considering intervention effects. In many variables, there were baseline differences between IS and CS. However, these baseline differences were not considered in the analysis.

All analysed questionnaire variables were in ordinal scale. New variables measuring the direction of the change were formed (positive change, no change and negative change). In order to create these new variables we examined the answers from years 2007 and 2008. If the answer was the same in both years there was no change, but if the participant reported, e.g. eating rye bread more frequently in 2008 than in 2007, the change was positive. These new variables were used to test the difference in changes between IS and CS. The difference was tested with Kendall's $\tau$-rank correlation coefficient. The reliability of the test result in the cluster-sampling framework was evaluated by a permutation test.
The intervention effects in nutritional variables were analysed with ANOVA in which the explanatory variables in the model were intervention group and the interaction intervention group school to take the effect of cluster sampling into account. Analyses were performed with the SAS statistical software package version $8 \cdot 2$ (SAS Institute Inc., Cary, NC, USA).

\section{Intervention}

The frame of reference of the intervention was Bandura's social cognitive theory according to which behavioural, cognitive and other internal factors interact with environmental factors ${ }^{(11)}$. The intervention consisted of various actions targeted at different actors and they were implemented at different times according to a planned schedule. The intervention actions focused on the development of a healthy food environment as well as on nutritional education. In developing the food environment, the main target groups were headmasters, teachers and school catering personnel who carried out the actions at schools after discussing with the study personnel. Nutritional education was implemented by the teachers during regular lessons.

In the food environment component, attention was paid to food-related attitudes. Drama workshops dealing with eating and school meals were organised both for teachers and pupils to improve their commitment to the intervention. Discussions and informative meetings with headmasters, teachers and school catering personnel were also arranged to discuss how they could improve the food environments in their own schools. To deliver information to the families, parents' meetings were organised in each school. Parents were offered a school meal and they were provided with information on the intervention and school meals. Furthermore, a magazine dealing with healthy eating was delivered to all parents. Pupils, parents and teachers also received information on the results of the baseline study concerning their own school.

The food environment component also included improvement of the supply of healthy snacks available at school. Supply of sugary snacks was restricted; for example, vending machines containing sweets and soft drinks were removed, and in schools offering snacks for sale the selection of snacks was improved to include sandwiches, milk and fruit instead of sweet cakes, etc. In two schools not offering snacks, vending machines selling healthy snacks were introduced. Several actions were also implemented during the year to increase the appreciation of the school lunch and to encourage the eating of a balanced lunch daily. In Finnish schools, crisp bread is usually offered daily at lunch and fresh bread approximately once a week. During the intervention, the supply of fresh bread was increased, but the other components of the lunch were provided as usual. Free supply of fruit and vegetables at school was not improved. 
For nutritional education, various materials providing information on sugar, fibre, fruit and vegetables were offered for teachers to use, such as illustrative pictures of typical snacks, posters, informative brochures, games and tests. For example, the sugar test included a set of questions by which the pupils could assess their own sugar intake. Teachers were offered ready-planned lessons, but they were also encouraged to use these materials during their normal lessons according to their needs.

The implementation of the intervention was followed by a web-based follow-up system in which the teachers were asked to report the use of teaching material for each class. Because the teachers were allowed to freely choose the material they used, there were some differences between the schools. Overall, the implementation of the intervention was successful and the teaching material was actively used. After the study, the most popular parts of the intervention material were published on the Internet to be used freely in all schools (see http://www.jarkipalaa. $\mathrm{f}^{(12)}$ ). For evaluation of the intervention, pupils, parents, teachers and catering personnel were asked their opinions on the intervention and most of the feedback was positive.

\section{Results}

\section{Frequency of consumption}

The frequency of consumption of rye bread, sweets, fruit and vegetables according to the questionnaire data is reported in Table 1. Among girls, the frequency of consumption of rye bread increased $(P=0 \cdot 03$; Fig. 1$)$ and that of sweets decreased significantly $(P=0 \cdot 006$; Fig. 2$)$ in the IS compared to CS. Among boys, there were no significant differences between the IS and CS.

At baseline, the daily consumption of fresh vegetables was infrequent; of the girls $\sim 40 \%$, and of the boys $<30 \%$, reported eating them daily (frequencies of $6-7 \mathrm{~d}$ / week and more than once a day together). At follow-up, it was found that the frequency of daily consumption of vegetables decreased among boys and remained the same among girls in both school groups. Daily consumption of fruit remained nearly constant among IS pupils but decreased among CS boys (difference not statistically significant).

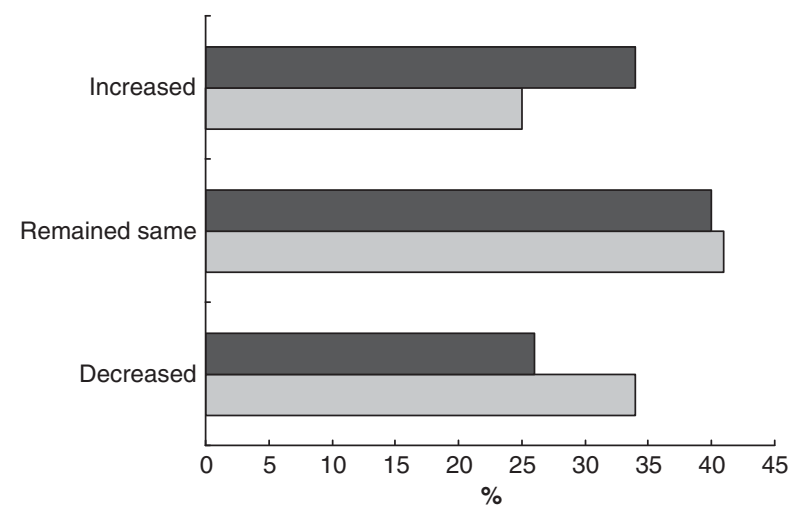

Fig. 1 Change in the frequency of consumption of rye bread among girls ( $\square$, intervention school; $\square$, control school)

Table 1 Frequency of consumption during the past week $(7 \mathrm{~d})$

\begin{tabular}{|c|c|c|c|c|c|c|c|c|}
\hline \multirow[b]{3}{*}{ Frequency of consumption } & \multicolumn{4}{|c|}{ Girls (\%) } & \multicolumn{4}{|c|}{ Boys (\%) } \\
\hline & \multicolumn{2}{|c|}{ Intervention ( $n$ 187) } & \multicolumn{2}{|c|}{ Control (n 182) } & \multicolumn{2}{|c|}{ Intervention ( $n$ 151) } & \multicolumn{2}{|c|}{ Control (n 139) } \\
\hline & 2007 & 2008 & 2007 & 2008 & 2007 & 2008 & 2007 & 2008 \\
\hline \multicolumn{9}{|l|}{ Rye bread } \\
\hline None & 4 & 6 & 3 & 4 & 6 & 11 & 7 & 13 \\
\hline $1-2 d$ & 25 & 20 & 21 & 26 & 23 & 31 & 30 & 32 \\
\hline $3-5 d$ & 41 & 37 & 36 & 36 & 36 & 27 & 33 & 30 \\
\hline $6-7 d$ & 18 & 24 & 28 & 22 & 20 & 17 & 16 & 15 \\
\hline$>1 / d$ & 12 & 13 & 13 & 12 & 16 & 14 & 15 & 10 \\
\hline \multicolumn{9}{|l|}{ Sweets } \\
\hline None & 23 & 28 & 24 & 24 & 21 & 20 & 19 & 22 \\
\hline $1-2 d$ & 49 & 52 & 58 & 56 & 58 & 62 & 57 & 56 \\
\hline $3-5 d$ & 24 & 18 & 14 & 20 & 20 & 16 & 21 & 20 \\
\hline $6-7 d$ & 4 & 1 & 3 & 1 & 1 & 2 & 2 & 2 \\
\hline$>1 / d$ & 1 & 1 & 1 & 0 & 0 & 1 & 1 & 0 \\
\hline \multicolumn{9}{|l|}{ Vegetables } \\
\hline None & 2 & 4 & 5 & 8 & 9 & 13 & 11 & 18 \\
\hline $1-2 d$ & 21 & 19 & 16 & 19 & 32 & 29 & 34 & 32 \\
\hline $3-5 d$ & 39 & 37 & 37 & 30 & 29 & 37 & 28 & 35 \\
\hline $6-7 d$ & 30 & 31 & 33 & 32 & 25 & 19 & 24 & 15 \\
\hline$>1 / d$ & 8 & 9 & 10 & 11 & 5 & 3 & 3 & 1 \\
\hline \multicolumn{9}{|l|}{ Fruit } \\
\hline None & 3 & 11 & 3 & 11 & 14 & 20 & 15 & 15 \\
\hline $1-2 d$ & 35 & 31 & 22 & 27 & 38 & 30 & 29 & 45 \\
\hline $3-5 d$ & 32 & 28 & 41 & 36 & 31 & 36 & 29 & 28 \\
\hline $6-7 d$ & 20 & 19 & 19 & 15 & 13 & 11 & 20 & 10 \\
\hline$>1 / d$ & 10 & 11 & 14 & 12 & 4 & 3 & 7 & 2 \\
\hline
\end{tabular}




\section{Snacks at school}

At baseline, the most commonly consumed snacks during school hours were sweets and sandwiches. In addition, girls ate cereal bars and fruit and boys drank sugary soft drinks (Table 2) Along with the intervention, there was some improvement in the quality of snacks. Girls in the IS reported a decrease in their consumption of sweets significantly compared with girls in the CS $(P=0 \cdot 03)$. Consumption of sugary soft drinks remained constant among boys in the IS, but at the same time increased significantly among boys in the CS $(P=0 \cdot 02)$. There were no differences

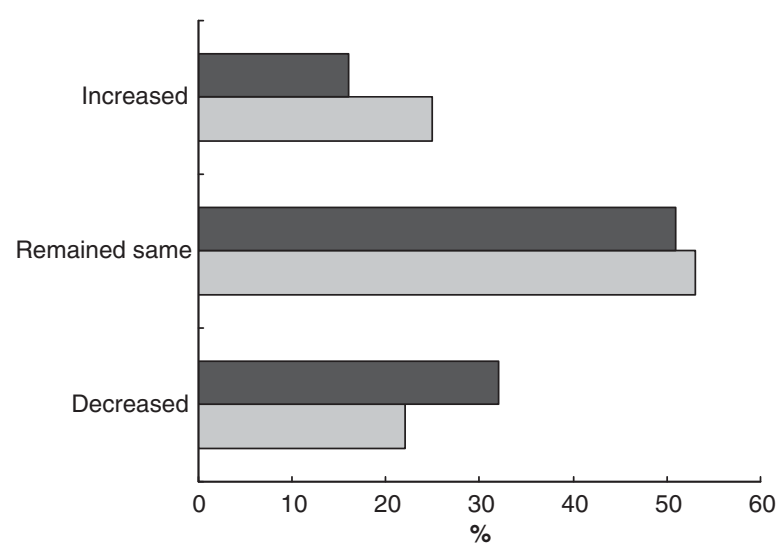

Fig. 2 Change in the frequency of consumption of sweets among girls ( $\square$, intervention school; $\square$, control school) in the changes of consumption of bread and fruit as snacks between IS and CS (Table 2).

\section{Results of the dietary recall}

As can be seen in Table 3, energy-adjusted consumption of fruit, including berries $(\mathrm{g} / \mathrm{MJ})$ remained constant in IS, whereas it decreased in CS (difference in change, $P=0 \cdot 04)$. There was no significant change in the consumption of vegetables.

The nutrient intakes among pupils in IS and CS and the changes between the years are presented in Table 4. At baseline, the intake of sucrose was higher and the intake of fibre lower than recommended. The intake of sucrose fell significantly among IS pupils (difference in change, $P=0 \cdot 01$ ). The decrease in sucrose intake in IS was $18 \%$ from the baseline value. There was no change in the intake of fibre. Furthermore, the intake of folate/MJ increased along with intervention $(P=0 \cdot 04)$.

\section{Discussion}

This intervention study succeeded in decreasing the intake of sucrose among secondary-school pupils. High sucrose intake has been associated with poor quality of diet ${ }^{(13)}$. If the decrease in the consumption of sugary drinks persists longer, it can have positive health effects both on dental health ${ }^{(14)}$ and weight ${ }^{(15)}$. A focus in this

Table 2 Snacks and drinks consumed during school hours

\begin{tabular}{|c|c|c|c|c|c|c|c|c|}
\hline & \multicolumn{4}{|c|}{ Girls (\%) } & \multicolumn{4}{|c|}{ Boys (\%) } \\
\hline & \multicolumn{2}{|c|}{ Intervention (n 187) } & \multicolumn{2}{|c|}{ Control (n 182) } & \multicolumn{2}{|c|}{ Intervention (n 151) } & \multicolumn{2}{|c|}{ Control (n 139) } \\
\hline & 2007 & 2008 & 2007 & 2008 & 2007 & 2008 & 2007 & 2008 \\
\hline Bread & 35 & 29 & 46 & 41 & 25 & 24 & 35 & 27 \\
\hline Hamburgers/pizzas/meat pasties & 2 & 4 & 2 & 2 & 5 & 7 & 4 & 12 \\
\hline Fruit & 19 & 19 & 36 & 31 & 5 & 3 & 9 & 4 \\
\hline Sweets & 46 & 41 & 28 & 35 & 34 & 41 & 32 & 45 \\
\hline Cereal bars & 26 & 29 & 31 & 35 & 8 & 12 & 7 & 9 \\
\hline Fruit juice & 5 & 11 & 7 & 3 & 7 & 5 & 4 & 5 \\
\hline Sugary juice & 7 & 4 & 6 & 8 & 11 & 9 & 7 & 9 \\
\hline Sugary soft drink & 12 & 11 & 7 & 7 & 18 & 18 & 17 & 30 \\
\hline Light drinks & 5 & 4 & 6 & 6 & 8 & 5 & 9 & 13 \\
\hline Energy drinks & 1 & 4 & 4 & 6 & 7 & 15 & 12 & 20 \\
\hline Tap water & 25 & 34 & 31 & 31 & 21 & 17 & 20 & 17 \\
\hline
\end{tabular}

Table 3 Amount of total vegetables and fruit consumed

\begin{tabular}{|c|c|c|c|c|c|c|c|c|c|c|c|c|c|c|c|c|c|c|}
\hline & \multicolumn{6}{|c|}{ Girls } & \multicolumn{6}{|c|}{ Boys } & \multicolumn{6}{|c|}{ Altogether } \\
\hline & \multicolumn{3}{|c|}{ Intervention ( $n$ 79) } & \multicolumn{3}{|c|}{ Control (n 80) } & \multicolumn{3}{|c|}{ Intervention (n 68) } & \multicolumn{3}{|c|}{ Control (n 60) } & \multicolumn{3}{|c|}{ Intervention (n 147) } & \multicolumn{3}{|c|}{ Control (n 140) } \\
\hline & 2007 & 2008 & Change & 2007 & 2008 & Change & 2007 & 2008 & Change & 2007 & 2008 & Change & 2007 & 2008 & Change & 2007 & 2008 & Change \\
\hline Vegetables (g) & 122 & 124 & 2 & 133 & 131 & -2 & 108 & 114 & 6 & 112 & 104 & -8 & 116 & 119 & 3 & 124 & 120 & -4 \\
\hline Vegetables (g/MJ) & 19 & 21 & 2 & 21 & 22 & 1 & 13 & 15 & 2 & 15 & 13 & -2 & 16 & 18 & 2 & 18 & 18 & 0 \\
\hline Fruit $(\mathrm{g})$ & 210 & 211 & 1 & 208 & 163 & -45 & 184 & 172 & -12 & 181 & 171 & -10 & 198 & 193 & -5 & 196 & 167 & -29 \\
\hline Fruit $(g / M J)^{*}$ & 31 & 33 & 2 & 34 & 25 & -9 & 22 & 21 & -1 & 23 & 20 & -3 & 27 & 28 & 1 & 29 & 23 & -6 \\
\hline
\end{tabular}

*Statistically significant difference in change (girls and boys together, $P<0.05$ ). 


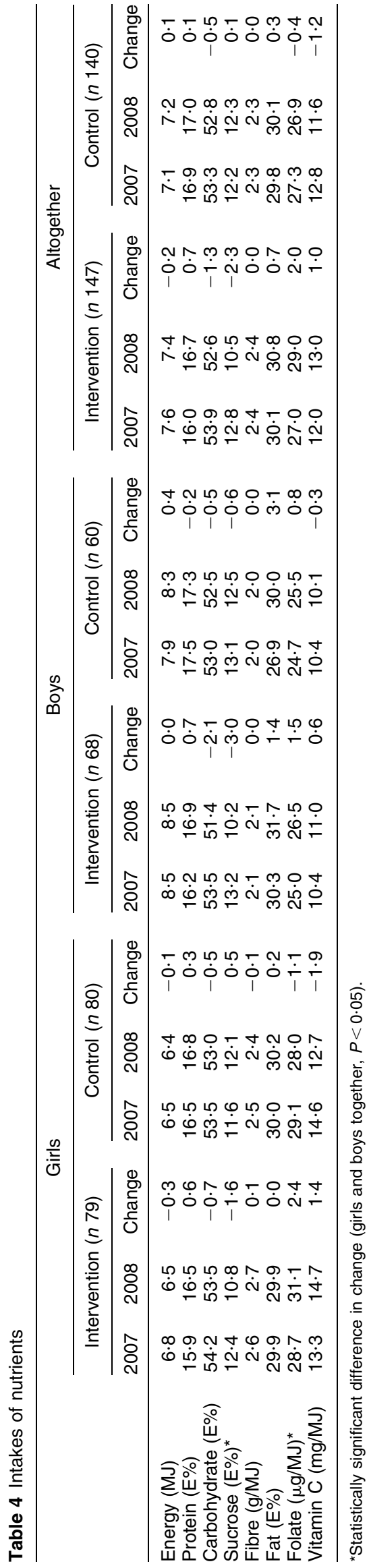

intervention was the snacks eaten at school, but other sources of sucrose, such as cereals and yoghurts commonly eaten for breakfast at home, should also be targeted to further decrease sucrose intake. Although the supply of fresh bread was increased at school lunch and the girls in the IS reported eating rye bread more often, the intake of fibre did not change. It is possible that the consumption of other sources of fibre has decreased concomitantly. It has also been reported that dietary fibre intake ( $\mathrm{g} / \mathrm{MJ})$ seems to stay fairly constant during adolescence ${ }^{(16)}$.

The intervention did not succeed in its aim of increasing the consumption of fruit and vegetables. However, the intake of fruit remained stable in the IS, whereas it decreased in the CS. This can be regarded as a good result, since it has been observed that the consumption of fruit and vegetables seems to decrease with age $^{(17,18)}$. In this intervention, education material on fruit and vegetables was used, but the supply of fruit and vegetables at schools could not be improved. It is not surprising that increasing knowledge is not easily turned into action if the supply of fruit and vegetables is not improved both at school and at home ${ }^{(19)}$. Other interventions, which have included the distribution of fruit or vegetables at school, have shown small positive changes ${ }^{(20)}$, but this may not result in sustainable changes. A combination of various personal and social factors has been observed to be related to fruit and vegetable intake, and therefore, multi-level intervention strategies are suggested $^{(21,22)}$.

School food policies have been shown to have an impact on adolescents' food habits ${ }^{(23-25)}$. Improvement in the supply of healthy foods at school, both as school lunch and snack options, has been the focus of many recent interventions and projects ${ }^{(26)}$. In this intervention, changes in the supply of snacks at school resulted in some improvements in pupils' snack choices. The selling of unhealthy snacks at school is in contrast with the health education aims of the curriculum and puts pupils' potential choices in conflict. It is the responsibility of all the adults at school, headmasters, teachers and catering personnel, to create a supportive environment for healthy eating and to make healthy choices easy for pupils.

The age group of 14-15-year old is challenging, as the changes related to puberty are rapid at this age. For example, among boys the rapid growth spurt may cause a considerable increase in energy needs ${ }^{(27)}$. It seems that along with age, eating habits may change in a more unhealthy direction $^{(17)}$, and, therefore, this trend should be stopped as early as possible. The intervention period was also short, at less than one school year. To achieve more permanent results, a longer intervention time starting at a younger age would be desirable. The strength of this intervention was that it was wide, with many actions targeted at many actors. However, a limitation is that it is not possible to identify the single actions that were the most effective. 
Some differences between boys and girls were observed in the results of the intervention. As in previous studies, the results have often been found to be better among girls ${ }^{(28,29)}$. This may partly be explained by different taste preferences of boys and girls; for example, girls have been found to like vegetables more than boys ${ }^{(30)}$. Thus, it is necessary to find new and effective intervention methods targeted specifically at boys.

This intervention was only targeted at eighth grade pupils. In order to get the whole school community to be more involved, interventions targeted at all pupils at school would be desirable. In Finnish comprehensive schools, grades 7-9 are usually located in the same building, so at least all these classes could be included. More involvement of the participants themselves in the planning and implementation of the intervention would also be an advantage. Good results have been observed in peer-led health education $^{(31)}$. The interest of adolescents in answering traditional questionnaires may be limited and new attractive data collection methods, e.g. via the Internet, should also be developed in the future ${ }^{(32)}$. The limitation of the present study is the low participation rate, but other school studies requiring active parental consent have often had low participation rates ${ }^{(33)}$.

Parents are responsible for providing healthy foods at home and they are also important role models for their children $^{(34)}$. However, some parents seem not to have the time for or much interest in the food habits of their children, and are not willing to participate in meetings at school. Improving parental involvement in interventions is a challenge and new communication strategies to reach the parents should be sought out.

In conclusion, this intervention study succeeded in decreasing the sucrose consumption of Finnish secondary-school pupils. The feedback on the intervention was positive both from the teachers and pupils. Participation of pupils in the planning and implementation of the intervention should be improved in the future. The experiences gained in the present study offer encouragement for continuing to develop school-based healthy eating promotion for adolescents.aaa

\section{Acknowledgements}

The authors thank all the schools and pupils for their participation and SITRA (Finnish Innovation Fund) for funding the study.

\section{References}

1. Pérez-Rodrigo C \& Aranceta J (2001) School-based nutrition education: lessons learned and new perspectives. Public Health Nutr 4, 131-139.

2. Hoelscher DM, Evans A, Parcel GS et al. (2002) Designing effective nutrition interventions for adolescents. J Am Diet Assoc 102, Suppl., S52-S63.
3. Thomas H (2006) Obesity prevention programs for children and youth: why are their results so modest? Health Educ Res 21, 783-795.

4. Shaya FT, Flores D, Gbarayor CM et al. (2008) School-based obesity interventions: a literature review. J Sch Health $\mathbf{7 8}$, 189-196.

5. National Nutrition Council (2005) Suomalaiset Ravitsemussuositukset (In Finnish, title in English: Finnish Nutrition Recommendations - Diet and Physical Activity in Balance). Committee report. Helsinki: Edita Publishing Oy; available at http://www.evira.fi/portal/vrn/en/nutrition_ recommendations/

6. National Nutrition Council (2008) Kouluruokailusuositus (In Finnish, title in English: Dietary Guidelines for School Meals). Helsinki: Savion Kirjapaino Oy.

7. Kankaanpää R, Lahti S, Manninen M et al. (2007) Makeisten ja virvoitusjuomien myynti perusopetuksen 7-9. luokkien kouluissa (In Finnish, abstract in English: selling sweets and soft drinks for primary school classes 7-9). Suom Hammaslääkäril 18, 964-972.

8. Story M, Neumark-Sztainer D \& French S (2002) Individual and environmental influences on adolescent eating behaviors. J Am Diet Assoc 102, Suppl., S40-S51.

9. Roos EB, Karvonen S \& Rahkonen O (2004) Lifestyles, social background and eating patterns of 15 -year-old boys and girls in Finland. J Youth Stud 7, 331-349.

10. Hoppu U, Lehtisalo J, Tapanainen H et al. (2009) Dietary habits and nutrient intake of Finnish adolescents. Publ Health Nutr (in this issue).

11. Bandura A (1986) Social Foundations of Thought and Action. A Social Cognitive Theory. Upper Saddle River, NJ: Prentice-Hall.

12. Keso T, Lehtisalo J \& Garam S (2008) Järkipalaa-käsikirja. Ideoita nuorten ruokailuympäristön kehittämiseen ja nuorten ravitsemuskasvatukseen. Leipätiedotus. http:// www.jarkipalaa.fi (accessed March 2010).

13. Ruottinen S, Niinikoski H, Lagström H et al. (2008) High sucrose intake is associated with poor quality of diet and growth between 13 months and 9 years of age: the special Turku Coronary Risk Factor Intervention project. Pediatrics 121, e1676-e1685.

14. Touger-Decker R \& van Loveren C (2003) Sugars and dental caries. Am J Clin Nutr 78, 881S-892S.

15. Vartanian LR, Schwartz MB \& Brownell KD (2007) Effects of soft drink consumption on nutrition and health: a systematic review and meta-analysis. Am J Public Health 97, 667-675.

16. Alexy U, Kersting M \& Sichert-Hellert W (2006) Evaluation of dietary fibre intake from infancy to adolescence against various references - results of the DONALD Study. Eur J Clin Nutr 60, 909-914.

17. Lien N, Lytle LA \& Klepp KI (2001) Stability in consumption of fruit, vegetables and sugary foods in a cohort from age 14 to age 21. Prev Med 33, 217-226.

18. Larson NI, Neumark-Sztainer D, Hannan PJ et al. (2007) Trends in adolescent fruit and vegetable consumption, 1999-2004. Project EAT. Am J Prev Med 32, 147-150.

19. Bere E, Veierod MB, Bjelland $\mathrm{M}$ et al. (2006) Outcome and process evaluation of a Norwegian school-randomized fruit and vegetable intervention: Fruits and Vegetables Make the Marks (FVMM). Health Educ Res 21, 258-267.

20. Reinaerts E, de Nooijer J, Candel M et al. (2007) Increasing children's fruit and vegetable consumption: distribution or a multicomponent programme? Public Health Nutr 10, 939-947.

21. Knai C, Pomerleau J, Lock K et al. (2006) Getting children to eat more fruit and vegetables: a systematic review. Prev Med 42, 85-95.

22. De Bourdeaudhuij I, te Velde S, Brug J et al. (2008) Personal, social and environmental predictors of daily fruit 
and vegetable intake in 11-year-old children in nine European countries. Eur J Clin Nutr 62, 834-841.

23. Kubik MY, Lytle LA, Hannan PJ et al. (2003) The association of the school food environment with dietary behaviours of young adolescents. Am J Public Health 93, 1168-1173.

24. Neumark-Sztainer D, French SA, Hannan PJ et al. (2005) School lunch and snacking patterns among high school students; associations with school food environment and policies. Int J Behav Nutr Phys Act 2, 14.

25. Vereecken CA, Bobelijn K \& Maes L (2005) School food policy at primary and secondary schools in BelgiumFlanders: does it influence young people's food habits? Eur J Clin Nutr 59, 271-277.

26. Suarez-Balcazar Y, Redmond L, Kouba J et al. (2007) Introducing systems change in the schools: the case of school luncheons and vending machines. Am J Community Psychol 39, 335-345.

27. Deheeger M, Bellisle F \& Rolland-Cachera MF (2002) The French longitudinal study of growth and nutrition: data in adolescent males and females. J Hum Nutr Dietet 15, 429-438.
28. Shepherd J, Harden A, Rees R et al. (2006) Young people and healthy eating: a systematic review of research on barriers and facilitators. Health Educ Res 21, 239-257.

29. Haerens L, de Bourdeaudhuij I, Maes L et al. (2007) The effects of a healthy eating intervention on adolescents' fat and fruit intake and soft drink consumption. Public Health Nutr 10, 443-449.

30. Cooke LJ \& Wardle J (2005) Age and gender differences in children's food preferences. Br J Nutr 93, 741-746.

31. Mellanby AR, Rees JB \& Tripp JH (2000) Peer-led and adultled school health education: a critical review of available comparative research. Health Educ Res 15, 533-545.

32. Matthys C, Pynaert I, de Keyzer W et al. (2007) Validity and reproducibility of an adolescent wed-based food frequency questionnaire. J Am Diet Assoc 107, 605-610.

33. Esbensen FA, Melde C, Taylor TJ et al. (2008) Active parental consent in school-based research: how much is enough and how do we get it? Eval Rev 32, 335-362.

34. Pearson N, Biddle SJH \& Gorely T (2009) Family correlates of fruit and vegetable consumption in children and adolescents: a systematic review. Public Health Nutr 12, 267-283. 